\title{
The Dragonfly's Web: Courseware for children created by college students on the World-Wide Web
}

\author{
CHRISTOPHER R. WOLFE and CHRISTOPHER A. MYERS \\ Miami University, Oxford, Ohio
}

\begin{abstract}
We describe a successful approach to teaching first-year undergraduates to produce World-Wide Web courseware. Students were responsible for coding, writing, graphics, research, and theory. We taught that courseware should elicit higher order cognitive processes such as problem solving, application, synthesis, and critical thinking in children. It appears that the exercise facilitated experiential learning, the application of theories of learning, and courseware and hypertext design, as well as promoting critical thinking in our undergraduates. We argue that psychology students can and should develop useful Web pages as a learning experience and service to the field.
\end{abstract}

The World-Wide Web (WWW, or Web) is the fastest growing segment of the Internet (Hayes, 1994), and with over 20 million people currently connected to the Internet, it may be the ultimate "vanity press." At almost no cost, even novice users may create Web pages that can be accessed by millions of users, and there are tens of millions of Web pages available to each user. Clearly, the WWW is likely to have a major impact on many aspects of psychology, including scholarly communication (Mainwaring, 1996), peer-refereed scientific journals (Plaud, 1996), and teaching (Krantz \& Eagley, 1996). Although psychologists and psychology students are likely to be major consumers of information on the WWW, they can (and should) also be major producers of WWW hypermedia. This paper describes a successful approach to teaching novice firstyear undergraduate students to produce useful, interactive educational hypermedia for the WWW.

The context of these exercises was an interdisciplinary course, required of all first-year majors of the Western College Program at Miami University, titled Learning from Information Technology. The course integrated materials from computer science, cognitive psychology, and other disciplines. A major goal of the course was to explore the potential role of networked computers in the "life of the mind," blending critical thinking and imagination, theory and practice, reading, and hands-on experience. As the final exercise of the course, undergraduate students created the Dragonfly's Web, science-oriented interactive hypermedia on the Web for children in Grades 3-6, based on solid design and learning principles, and incorporating images and text.

With the support of the National Science Foundation and Miami University's Center for Human Development,

Correspondence should be addressed to C. R. Wolfe, Western College Program, Miami University, Oxford, OH 45056 (e-mail: crwolfe@ miavx1. acs.muohio.edu).
Learning, and Teaching, Project Dragonfly (Myers, Cummins, Haynes, Marcuccio, \& Wolfe, 1994) will premier in April of 1996. Project Dragonfly (PDF) includes an interdisciplinary journal of science and nature for children in Grades 3-6, supporting teacher and home companions, a complementary listserv list connecting children and scientists, and the Dragonfly's Web page (http://miavxl. muohio.edu/ Dragonfly/). Dragonfly is inquiry based, and the first national publication devoted to the voices of children and research scientists as well as to science conducted by children.

Trees were selected as the unifying theme of the first issue of the Dragonfly journal and the Dragonfly's Web. The four topics of the WWW hypermedia (one for each section of the course) are as follows: the interaction between squirrels and forests, seed dispersal, alleleopathy (chemical products produced by some plants to prevent competing plants from growing), and tree architecture/ morphology. Children were selected as the target audience of our Web pages because we perceive that the needs of children are underrepresented on the World-Wide Web. We believe that, with proper guidance, undergraduates are capable of producing quality courseware for children. This assignment thus allowed undergraduates to apply tools from psychology and information technology to a real-world application.

The goals of this exercise for our undergraduate students were to facilitate student-directed experiential learningby-doing (Kolb, 1984); to help students learn to apply cognitive theory and theories of courseware and hypertext development and to teach specific computer skills and promote quantitative reasoning (Wolfe, 1993); and to promote critical thinking about courseware, hypermedia, and the WWW (Wolfe, 1995).

\section{Method and Procedure}

The students were approximately 60 first-year undergraduates enrolled in four sections of a required course, Learning from Infor- 
mation Technology. Only 1 student had had previous experience with the hypertext markup language (HTML) or the WWW. At the beginning of the course, several students sald they were intimidated by the idea of working with computers. Prior to this exercise, students engaged in a variety of preparatory activities. Students learned to create their own hypertexts using Hypercard on the Macintosh (Wolfe, 1995). Students became acquainted with the Web by means of free exploration, a "scavenger hunt" for information, and directed exploration of a collection of Web pages designed for children (maintained at http://miavx 1.muohio.edu/ crwolfe/ kid_links.htmlx) and adults (maintained at http://miavx 1.muohio.edu/ crwolfe/hot_links. $\mathrm{htmlx}$ ). Students also explored and evaluated courseware (educational software) and hypertexts after reading and discussing a number of articles on learning theory and courseware and hypertext design, including, for example, those by Steinberg (1991), Jonassen, (1988), Resnick (1989), and Papert (1984).

Each section of Learning from Information Technology was divided into five groups, with each group being responsible for a specific aspect of the final hypermedia product. Group 1, the Research and Development (R \& D) group, was responsible for researching the theme and making sure substantive and accurate scientific knowledge was incorporated into the hypermedia. Group 2, the text group, was responsible for the hypertext narrative structure and writing for children. Group 3, the graphics group, was responsible for producing all images and putting them in GIF format. Group 4 , the web-weaving (coding) group, was responsible for actually coding the HTML interface for the WWW. Group 5, the cognitive psychology and Dragonfly philosophy group (CPDP), had the task of ensuring that educational goals were employed that encourage chlldren to interact, think, and learn.

We discussed with students how learning theory applied through the Dragonfly's Web should inspire reflection and questioning, teach scientific processes, and include children of diverse backgrounds. We stressed to our students that the effectiveness of courseware is a function of the behaviors it elicits from children. We emphasized behaviors associated with higher order cognitive processes such as synthesis, integration, and application. Hypermedia should not be a static collection of facts. Rather, children should be challenged to go outside, take a new look at the world, and begin their own investigations. A central objective was to teach about the process of science, rather than simply dazzling children with "high-tech bells and whistles." Courseware should engage children in the creative process of thoughtful inquiry, encouraging children to entertain different hypotheses, methods, and conclusions, and to think and interpret for themselves.

We told students that their work would be evaluated on the basis of science content, educational value, technical expertise, and creativity. Each student received an overall grade for the final project, a group grade, and an individual contribution grade. Students were also told that "final products that are up to national standards will be shared with the National Science Teachers Association, the $\mathrm{Na}$ tional Science Foundation, and will be maintained on-line for children" (PDF is a collaborative effort of the National Science Teachers Association and Miami University supported by a 3-year grant from the National Science Foundation).

Students created the Web pages over a period of approximately 5 weeks. During this phase of the course, the instructors took on the role of facilitators, working closely with each group, as well as with the class as a whole. Each class session started with a meeting of the class as a whole to assess where we were and what our next steps would be. Then, students broke into groups and worked independently while the instructors and undergraduate assistants moved between groups, offering comments and assistance (and putting out occasional "fires").

The R \& D teams had the task of conducting the initial library research and sharing their findings with the rest of the class (and assigning them a set of readings). The general topic was assigned by the instructor, but the specific nature of each Web page was decided by the class as a whole through a process of initial brainstorming followed by discussion and consensus. The R \& D groups had the added responsibility of ensuring that the writing teams produced scientifically accurate texts.

Although the Web pages were assembled on one of Miami's DEC Alpha computers, most of the production work was done in the School of Interdisciplinary Studies Center for Computer Assisted Learning (SISCCAL), a networked Macintosh environment. The writing groups used Microsoft Word 5.1, saving their work in ASCII format as "text only." Their task was to express scientific concepts in ways that children can understand and appreciate. The graphics groups used a number of tools, including an Epson color flatbed scanner to digitize photos, and Photoshop 3.0 (Adobe Systems Inc., Mountain View, CA), and Canvas 2.0 (Deneba, Miami, FL) to draw and manipulate images. Images were converted to the GIF format (the most widely used image format on the WWW) with a shareware program called GIFConverter 2.3.7 (Kevın A. Mitchell, Chicago, IL). Text and image files were transferred ("FTPed") to the Alpha using Fetch 2.1 (Dartmouth College, Hanover, NH), and we used the NetScape 1.0 (Netscape Communication Corporation, Mountain View, CA) WWW browser.

Students in the Web-weaving groups were assisted by on-line HTML documents, such as the NetScape Handbook (http://home. netscape.com/eng/mozilla/1.1/handbook/). A useful tool for learning HTML is the Source option under the View menu in the NetScape browser, which allows users to see the HTML code used to construct any page on the WWW. Most students learned from experience, moving back and forth between their HTML code and the NetScape browser. They received assistance from the instructors and from one another. Finally, in addition to ensuring that the projects were consistent with the principles of project Dragonfly, the CPDP teams had the additional task of creating suggested exercises for children to conduct "in the field."

\section{Results and Discussion}

Novice undergraduate students produced four interactive, educational hypermedia Web pages for the Dragonfly's Web in "working areas" on a DEC Alpha computer. The topics were squirrels and acorns, seed dispersal, allelopathy, and tree architecture/morphology. Each of these Web pages is quite distinct in its character and approach. For the sake of brevity, we will focus on The Shape of Trees, the product of the tree architecture/morphology section. The Web page starts with introductory pictures and text describing some of the factors associated with differences in the general shape of trees. It focuses on selected species in three locations, including a coniferous forest in Alaska, a temperate forest in Ohio, and a rain forest in Costa Rica. Children are then invited to play a game in which they "design" a tree to adapt to a particular environment.

In the first round, children are instructed to design a tree to grow in the understory of a temperate forest. They choose between tree heights of 8 or 33 meters; flat, round, or conical branch design; and broad leaves or pine needles. After the child designs a tree for a particular environment, he or she will see a picture of the tree, along with specific feedback about its chances of survival (Figure 1). In the case of an inappropriate response, the child may try again, or move on to another environment. After designing trees for three environments, the child is given a field exercise on the Fibonacci number series and plant geometry. 


\section{Congratulations!}

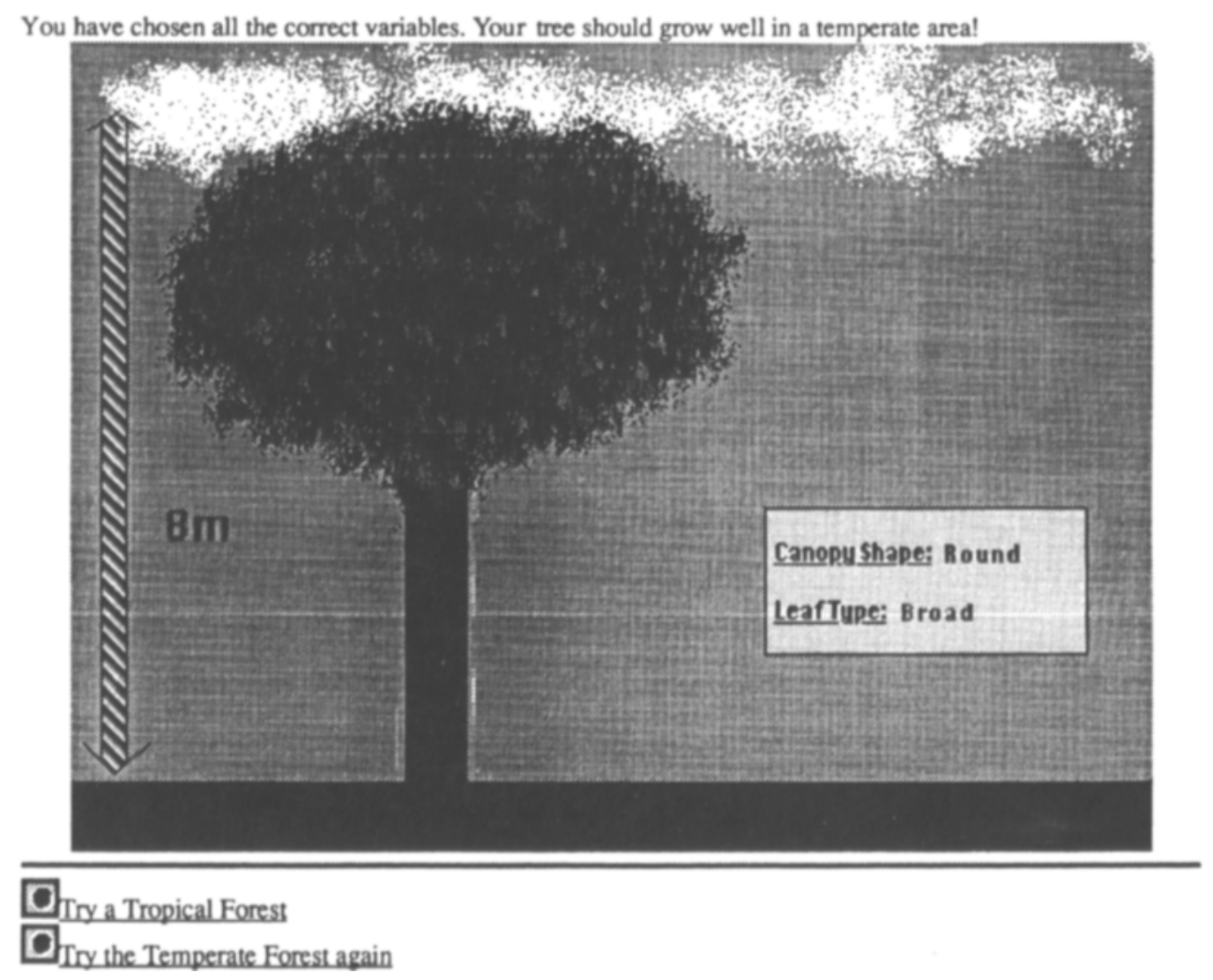

Figure 1. World-Wide Web page from The Shape of Trees.

In the judgment of the authors, all four of the WWW hypermedia projects were very good, though none was ready to be used by children without significant editing. As a learning experience for our undergraduate students, the exercise was assessed by the written comments of students (and by the "existence proof" that they actually learned enough to complete the project - which arguably might be considered a form of "authentic assessment"; Bergen, 1994). Students' comments were generally positive. Many expressed surprise at their ability to create working hypermedia on the WWW and claimed that they had learned from the experience. For example, one student said, "It really was a good end to the class because it draws together all of the stuff that we have learned about educational software and made us apply all the knowledge that we have acquired over the semester." Many students expressed a desire to have more time and were frustrated at their inability to envision the final product. There were also some difficulties with between-group cooperation (many in the Web-weaving groups were frustrated that they had to wait for others before they could begin their work). Some students expressed an interest in working in more than one group. Several students also expressed a desire to have more control over the theme of their Web pages.
In the future we will devote more time to this project. A key component of courseware development, and one that was missing from this experience, is collecting data from users. We plan to have our students pilot test their work on real fifth graders; they will collect and analyze preliminary data, and then revise the Dragonfly's Web accordingly. We also plan to experiment with the organization of teams. In the course reported here, students worked in teams on different components of the Dragonfly's Web pages. This might be labeled a "horizontal" organization in that the results of one group are "laid upon" the next. We plan to experiment with a "vertical" organization in which the larger task is divided into smaller units that are brought from inception to completion by each team. Thus, students in each team will be responsible for creating images and text and coding them in HTML. Such an approach might give students experience with a number of dimensions of the process, while keeping the task manageable.

In our experience, many 1st-year undergraduates have difficulty taking themselves seriously intellectually. Participating in an exercise with real-world consequences proved more motivating for some students than typical academic assignments. For example, one student said, "It is very interesting and fun to see your own work right 
in the Internet, and I think it's cool to know that students somewhere are benefiting from our work. I learned a lot from this project." In our course, creating science-oriented courseware for children was the theme of the Dragonfly's Web. However, we believe, on the basis of our experience, that novice undergraduates in psychology courses can and should create courseware and other materials for psychology students on the Web. Many colleges and universities offer courses on computers and psychology that would be especially appropriate for such an exercise. We envision a time when psychology students around the world will develop useful Web pages as both a learning experience and a service to the field. For example, students in a course on perception might create WWW demonstrations of visual illusions, and introductory psychology students might post data from demonstration experiments. These illusions could be used in a psychology course at another college, and the raw data could be analyzed by statistics students at another university. An organization such as the Society for Computers in Psychology (SCiP) seems like a natural repository for annotated WWW links to these Web sites. In any case, in our experience, undergraduate novices are capable of producing good work on the WWW and more than capable of learning from the experience.

\section{REFERENCES}

Bergen, D. (1994). Authentic performance assessments. Childhood Education, 70, 99-102.

HAYES, B. (1994). The World Wide Web. American Scientist, 82, 416420 .
JONASSEN, D. H. (1988). Integrating learning strategies into courseware to facilitate deeper processing. In D. H. Jonassen (Ed.), Instructional designs for microcomputer courseware (pp. 151-181). Hillsdale, NJ: Erlbaum.

KoLB, D. (1984). Experiential learning: Experience as the source of learning and development. Englewood Cliffs, NJ: Prentice-Hall.

KrantZ, J. H., \& EaGLEY, B. M. (1996). Creating psychological tutorials on the World-Wide Web. Behavior Research Methods, Instruments, \& Computers, 28, 156-160.

MaINWARING, S. (1996). Compilation and use of a World-Wide Web index of cognitive and psychological science resources. Behavior Research Methods, Instruments, \& Computers, 28, 152-155.

Myers, C. A., Cummins, R. H., Haynes, C., Marcuccio, P., \& Wolfe, C. R. (1994). Project Dragonfly: An alliance of scientists, teachers, and children for elementary science education (National Science Foundation Program for Instructional Materials Development Grant No. ESI-9550538).

PAPERT, S. (1984). Computer as mudpie. In D. Peterson (Ed.), Intelligent schoolhouse (pp. 17-26). Reston, VA: Reston Publishing.

Plaud, J. J. (1996, November). Creating a peer-reviewed journal on the WWW: Journal of Behavior Analysis and Therapy ( $j B A T)$. Paper presented at the meeting of the Society for Computers in Psychology, Los Angeles.

ReSNICK, L. B. (1989). Introduction. In L. B. Resnick (Ed.), Knowing, learning, and instruction: Essays in honor of Robert Glaser (pp. 1-14, 23-24). Hillsdale, NJ: Erlbaum.

SteinberG, E. R. (1991). A framework for CAI. In E. R. Steinberg (Ed.), Computer-assisted instruction: A synthesis of theory, practice, and technology (pp. 21-50). Hillsdale, NJ: Erlbaum.

WOLFE, C. R. (1993). Quantitative reasoning across a college curriculum. College Teaching, 41, 3-9.

WOLFE, C. R. (1995). Homespun hypertext: Student constructed hypertext as a tool for teaching critical thinking. Teaching of Psychology, 22, 29-33.

(Manuscript received November 13, 1995; revision accepted for publication December 18, 1995.) 